DOI: 10.17805/zpu.2015.2.3

\title{
В поисках главной цели всеобщего обучения
}

\author{
Я. ЩВИРКО-ПИЛИПЧУК
}

(ЩЕЦИНСКИЙ УНИВЕРСИТЕТ, ПОЛЬША)

В статье делается попытка найти ответ на вопрос о том, что предпринимается в образовательных действиях в школах Польши, в каждом их типе и на каждом уровне обучения в отношении главной цели всеобщего обучения, которая ставится в рамках перемен и образовательных реформ после 1989 г.

На основе критического рассмотрения современной ситуации в польской системе образования показывается, что функцию цели образования все больше выполняют заключаемые в нем содержание и (или) действие. В итоге наблюдается феномен автономизации средств, которые независимо от цели получают равноправные с ней права и даже становятся выше, чем сама цель. 
Показывается, что либерализм был единственной официальной идеологией перемен в Польше после 1989 г., однако его влияние на общественные практики в сфере образования проявилось в формах неолиберализма. Соответственно, главной целью образования, в том числе и университетского, стала функциональная идентичность по отношению к системе свободного рынка.

Ключевые слова: образование, образовательная реформа в Польше, цель образования, неолиберализм.

$\mathrm{B}$ данной статье понятие «цель» понимается как наилучшее состояние (состояние, характеризуемое наивысшей степенью), являющееся для перемен одновременно чем-то начальным (причина) и конечным (результат перемен). П. Замойски предполагает, что двойственность цели обусловлена не разницей между внутренней причиной цели и наилучшим конечным состоянием, а различием между намерением, которое имплицирует разумные мысли, и добром, к которому приводят предпринятые согласно намерениям действия. Причем цель все это время является как чем-то начальным (намерение), так и конечным (добро). Однако, учитывая активное участие разумного существа в установлении цели, она является чем-то большим, а именно обоснованием действия, о котором можно спросить: по какой причине? для чего? зачем? А содержанием ответа на эти вопросы является добро. Это означает, следовательно, что «цель является определением того, к чему направлено данное стремление, а устремлено оно всегда к добру, которое представляет собой то, зачем данное стремление предпринимается» (Zamojski, 2010: 39; здесь и далее пер. наш. - Я. Щ.-П.).

Союз так понимаемой цели и действия можно рассматривать проспективно или ретроспективно. Учитывая проспективный подход, в котором существование конечной цели является зависимым от проектирующего сознания, мы говорим здесь о преднамеренности, которая направлена на осознание цели собственного действия. Таким образом, она является осознанием того, зачем я дейстьую; есть рациональное отражение, устанавливающее предел стремления, относительно которого можно требовать обоснования. «Поэтому преднамеренность является понятием более широким, чем намерение, т. е. представляет собой совокупность толкований предпринятых действий, которые не только проектируют, но и являются их ментальным багажом в виде обоснования, контроля и оценки. Обоснование, контроль и оценка возможны, собственно говоря, благодаря преднамеренности как интерпретации действий, которые определяют смысл соответствующих шагов, т. е. действий, которые составляют данное движение» (там же: 40-41). Так понимаемая преднамеренность относительно действий субъектов образования позволяет понятие «цель» употреблять в значении сознательной цели Аействия.

Цель обучения, являющаяся ответом на вопрос: «Учить чему и зачем? » — понимается как идея организации, смысла и обоснования процесса обучения, которое предпринимается, т. е. является чем-то начальным и конечным. «Говоря обыденным языком, является тем, о чем идет речь в обучении» (там же: 43).

Отвечая на так сформулированный вопрос относительно обучения в нашей стране после 1989 г., можно, конечно, принять за ответ формулировки, предложенные в проектах образовательных реформ (1999 г. и для высших учебных заведений - 2005 г.), а также в других документах органов просвещения, например в программных основах, стандартах обучения студентов и т. п. Однако, учитывая одни и те же формулировки, а также их анализ, появляющийся в публикациях по данной тематике (Czerepaniak-Walczak, 2005, 2013), можно согласиться с М. Аудзиковой в том, что цель обучения относится к категории мифов (Dudzikowa, 2004). 
Не пренебрегая мифами и их функциями в образовании, в поисках ответа на поставленный вопрос и с учетом предпринятых обучающих действий в наших школах, мы принимаем во внимание как нормативы, так и контекстное измерение социализации. Трактуя обучение как общественный процесс, мы принимаем, что между этими двумя измерениями может происходить реляция типа диалектического посредничества (Zamojski, 2005). Оно состоит во «взаимном посредничестве контекстного и нормативного измерения не в смысле логики “средство-цель”, а в смысле диалектики отношений. Соотношение этих измерений происходит на различных уровнях образовательного процесса и имеет своей целью предпринять усилия, чтобы понять процессы, состоящие из этих ситуаций, собственных действий и действий других участников» (там же: 88-89).

Чрезвычайно важно для обсуждаемой темы, что «этот тип реляций измерений обобществления означает то, что невозможно понять цель педагогического действия, не ссылаясь на его общественный контекст, и наоборот» (там же: 89). Это означает также, что для установки главной цели всеобщего обучения необходимо познание общественного контекста образовательного процесса и признание того, что именно такая, а не другая реально осуществленная цель определяет общественный контекст этих процессов как в виде содержания, так и педагогических действий.

Определяя ход и направление изменений в обществе после 1989 г., относительно образования можно сказать, что предложенные в проектах образовательных реформ определения целей обучения не учли произошедшие перемены и не создали идей по организации обучения. Неудачные попытки определить главную цель всеобщего обучения (расплывчатый мифический характер), сформулировать ее на уровне содержания и действий (формализация, инструментализация обучения), путаница функций целей, ценностей и средств, а также сопутствующая образовательным переменам довольно распространенная неприязнь к определению целей обучения вообще (желание деполитизировать образование) - все это создало своего рода вакуум в данной области. Как и следовало ожидать, он довольно быстро и плотно заполнился. Это произошло благодаря неолиберальному давлению культурного перелома.

В период после 1989 г. именно неолиберальная доктрина обозначила направления перемен в нашем образовании. Ее неконтролируемое и мгновенно распространяющееся господство как в общественной жизни, так и в образовании стало причиной специфической политической, общественной, нравственной ситуации в обществе. Обстановка в нашей стране в то время характеризовалась прежде всего радостью от только что полученной свободы, огромным желанием быть таким же обществом, как и другие зрелые демократические общества, потребностью быстро наверстать упущенное во всех областях, в частности в сфере частной собственности, и прежде всего огромным нетерпением в реформировании каждой из этих сфер (Koralewicz, Ziólkowski, 2003). Кроме того, при характеристике того периода необходимо учитывать историческую обусловленность классическо-либеральной мыслительной традиции, неразвитое гражданское общество, недостаток классических либеральных институтов (Lewartowska-Zychowicz, 2010).

Все это создало необычайно благоприятную почву для принятия решений, проверенных и осуществленных в других странах. Причем необходимо помнить, что именно в этот период параллельно существовали два явления: наш поспешный и торопливый переход от социализма к капитализму и переплетающаяся с этим переходом внутренняя перемена самого капитализма, его отход от либеральных принципов и получение неолиберального качества, одновременно определяющего общекультур- 
ные изменения. Как образно заметила И. Рутковяк, «мы хотели заменить трамвай, на котором ехали, но не заметили, что мы пересели и даже вскакивали на ходу уже не в тот трамвай, который был предметом наших желаний и воображений» (Rutkowiak, 2010: 15$)$.

Сложность ситуации в нашей стране, обусловленная среди прочего воздействием процессов глобализации как в экономической, так и культурной плоскостях, стала причиной того, что в большей части бессознательно и некритично мы приняли все основные предпосылки неолиберальной доктрины. Это произошло потому, что процессы глобализации выскальзывали из-под контроля общественных институтов, первичных групп и государства, провозглашая себя в качестве безличностных, рассеянных, невидимых, мнимых плюралистических феноменов, «интернализирующих Удовольствие», действующих не по принуждению, а по соблазну и в то же время пропагандирующих достаточно единое видение мира (Koralewicz, Ziólkowski, 2003; Rutkowiak, 2010: 14).

Аавление этих сил проявлялось также и в области образования. Однако в данной сфере реализация предпосылок неолиберализма, содержащаяся в проекте личности bomo oeconomicus, оказалась не слишком трудной, собственно, незаметной по отношению к бихевиористской парадигме обучения в соответствии с общей действующей практикой, в том числе и университетской. Многие решения принимались без отчетливого понимания основных предпосылок. Примером таких решений является введенная в 1999 г. школьная реформа, а также принятые в ее рамках программы, учительские и организационные практики. Часто всевозможные решения обосновывались необходимостью использования опыта других стран, однако принимались они без контекстно-критического анализа, а также без оценки вероятных последствий (Rutkowiak, 2010: 14).

Замечания о непрозрачности принципов, отсутствии «того, чему обучаем», образовательной стратегии, замена просвещения текущим администрированием и получение нелучших результатов легли в основу сформулированной И. Рутковяк гипотезы о функционировании образовательной программы корпоративной экономики. Подтверждение этой гипотезы в образовательной практике можно найти в публикациях И. Рутковяк, Е. Потулицкой, М. Черепаняк-Вальчак, 3. Кветиньского, Т. Шкудлярка, П. Замойского, А. Клус-Станьской, М. Новицкой (Klus-Stańska, Nowicka, 2005).

Неолиберальный перелом, начавшийся в 80-х годах минувшего столетия, опирался в теории на предпосылки Фридриха Августа фон Хайека и Милтона Фридмана, а в сфере практики - на решения Рональда Рейгана и Маргарет Тэтчер. Этот тип капитализма (турбокапитализм, согласно Э. Аюттваку) был принят некритично, без учета других решений, например, практикуемых в Скандинавии - социал-демократических. Это означало акцептацию таких принципов неолиберализма, как принцип самообладания (укрепление идеи независимости bomo oеconomicus), принцип свободного рынка (пространство экзистенции и развития человека), принцип разума и нравственности (орудия эффективного действия) и принцип свободы (контекст единичного действия вместо свободы как цели) (Lewartowska-Zychowicz, 2010: 166-210).

Турбокапитализм основан на механизме современной корпорации, которую можно кратко охарактеризовать следующим образом: «Корпорация не является нравственной единицей. Она существует, чтобы давать прибыль, и так должно быть» (Luttwak, 2000: 7). В реализации корпоративных целей большую роль играет так называемый человеческий капитал, что означает трактовку человека как әлемента экономического роста и получение пользы путем инвестирования в него, в частности в его 
образование. Причем здесь наиважнейшая прибыль, являющаяся эффектом игры свободного, ничем неограниченного рынка, - это прибыль не для людей, а возведенная над головами людей (Chomsky, 2000).

Приоритет прибыли достигается прежде всего путем стимулирования дюдей к соответствующим ментальным переменам. Речь идет о том, чтобы сделать прибыль важнейшей целью человеческой жизни, воплотить следующий принцип: «Имею, следовательно, сушествую. Являюсь тем, что имею, следовательно, чем больше имею, тем больще существую». В реализации так обозначенной цели и основного принципа корпоративного капитализма главную роль играют механизмы переработки людей в объекты следующих видов: 1) нерефлективных, а производительных; 2) ненасыщенных потребителей (причем потребление имеет большее значение, чем производство); 3) человеческие «отбросы», предназначенные «на помол» (Bauman, 2004) из-за их неспособности участвовать в интенсивном движении «производство-потребление» источнике приумножения корпоративной прибыли (Rutkowiak, 2010: 18).

Формирование таких людей является основой образовательной программы корпоративной экономики и усиливающейся «образовательной корпорации» (Potulicka, 1994).

Задачей образования в рамках создания вышеупомянутой общественной структуры является радикально состязательное селекционирование людей. Речь идет о выделении авангарда будущих технократов высшего класса, управляющих системой специалистов общественной инженерии и производителей, использующих так называемые ключевые навыки, которые действительно являются элементом адаптации человека к реальности с ограничением проникновения в его собственную ситуацию. 3десь важно, чтобы навыки, стандарт, процедура вытесняли мышление.

Особых образовательных операций требует формирование потребителей, так как каждый человек, первоначально не склонный к потреблению, должен стать страстным, ненасытным потребителем, теряющим собственное критически-контролируемое отношение к такому виду поведения. С этой целью используются маркетинговые стратегии сегментации, дифференциации, позиционирования. Выделяется также стратегия, называемая «маркетингом отношений», когда объектами управления становятся отношения между людьми и качества самих людей.

В соответствии с маркетинговым принципом сегментации в рамках «образовательной корпорации» весьма существенной группой потребителей являются люди, связанные с образованием: дети, молодежь, родители, учителя. Это они - потребители средств обучения и учения: книг, журналов, игр, компьютерных программ, электронного оборудования. Сами эти средства своим содержанием и графической формой формируют желаемого потребителя. Например, учебники для младших школьников, основанные на заполнении граф и вписывании единственно правильного ответа, способствуют реактивности, навыкам выбора из багажа данных, обучению «по следу» (определение А. Клус-Станьской), подчиненности и дисциплинированности. Но это не содействует интенсификации творческой интеллектуальной работы учащегося (там же: 19). Размеры этого явления весьма распространены, учитывая «привязанность» учителей к учебникам, доходящую порой до фетишизации школьных учебников.

Принцип дифференциации в системе образования осуществляется весьма отчетливо в образовательных рейтингах с помощью средств массовой информации. Это касается высших учебных заведений, школ, классов, учителей и самих учащихся. Аействуют с невероятной силой конкурентные отношения - «все против всех», при этом за- 
бывается, что сотрудничество и взаимодействие чрезвычайно существенны для общественного функционирования людей. Эти всеобщие состязания и селекция на основе как бы объективных проверок и әкзаменов по выбранным предметам не всегда соотносимы с результатами образовательных процессов.

В аналогичном направлении идет маркетинговое позиционирование, которое в образовании основано на принципах конкуренции и проявляется в упоре на депозиты желании получить дополнительные средства, гонке образовательного учреждения за более высоким местом и старании учащегося подняться на более высокую позицию, формировании карьеризма.

Вышеперечисленные принципы и механизмы используются также и в создании «людей за чертой» - с низкими культурными компетенциями, физически и психически слабыми, бессильными, неспособными, плохо организованными, нездоровыми, беспомощными в этой неолиберальной действительности. Распространяется мнение, что они сами несут ответственность за свою неудачу, так как они безвольные, плохо мотивированные, безучастные. «Аюди за чертой» являются предостережением для других, которые временно в выигрыше: вот что с ними будет, если они не проявят достаточной производительно-потребительской активности. Подобные представления закрепляются в сознании учащихся, в частности выпускников школ.

В неолиберальной идеологии школа трактуется как весьма важный фактор формирования молодого человека не только способами, которые официально закреплены в образовательных программах, но и путем скрытых программ. Они находят свое место в каждом структурном элементе обучения.

Анализ отдельных важнейших категорий нашей системы образования показывает, что ее основные элементы, принципиальные для протекания процесса обучения и результатов образования, - цели обучения и принятые ценности не выражены ясно и прозрачно в документах о реформе образования. Созданный «эпистемологический уникат» (Szkudlarek, 2004), который должен был бы охранять школу от идеологизации, по правде говоря, создает идеологический вакуум, мгновенно заполняемый ценностями и целями скрытой программы «образовательной корпорации», в том числе основной ее ценностью - прибылью и ожидаемым благополучием, которое учащиеся получат благодаря хорошим школьным результатам, подтвержденным, конечно, экзаменами.

Принимая во внимание «силу господства» экзаменационных тестов в школе в известных нам формах, в содержании обучения усиливается информационный элемент. Информация вытесняет познавательную установку на понимание и интерпретацию мира, являющуюся основой сознательного и критического функционирования в нем. В результате в образовании доминирует информация, а знания перестают быть важными, потому что часто думают, что они сформируются как-нибудь автоматически, без необходимости интенциональных образовательных операций в этой области. Выбор информации подготавливает к выбору товара на рынке. Ослабление, следовательно, интерпретационных и критических компетенций позволяет формировать арефлекторные единицы, которые не осознают своей позиции и даже довольны, принимают дихотомизацию, так как «неумелый в мышлении только с ним и мучается» (Rutkowiak, 2010: 24). Но неолиберальная стратегия требует хорошо подготовленных управляемых людей, которые беспроблемно подходят к действительности, эффективно в ней функционируют.

К сожалению, всякого рода предостережения в этой области (Kwiecinski, 2007) остаются без реакции, и экзаменационная процедура не подвергается сомнению, более 
того - она совершенствуется с организационно-технической точки зрения. Не учитывается и то, что идея внешнего проведения экзамена находится в противоречии с идеей децентрализации, принципом индивидуализации и принципом программного и педагогического плюрализма.

Учителя весьма важны в деле реализации корпоративной образовательной программы. К сожалению, многое указывает на то, что подавляющее их большинство являются носителями неолиберальной идеологии, хотя в малой степени осознают это. Это понятно, если учесть общественные условия их жизни, их собственный продолжительный образовательный опыт и прежде всего процесс их профессиональной подготовки в высшем учебном заведении на двух уровнях. Изменения в педагогическом обучении, введенные в рамках последней реформы высшего образования, отлично вписались в образовательный проект, отвечающий корпоративным интересам и воплощающий программу корпоративной экономики образования. Как утверждает М. Черепаняк-Вальчак, в процессе реформы академического образования наступает консервирование до сих пор действующих практик. Черепаняк-Вальчак пишет: «...peформаторы (проектировщики) академического образования убирают из поля зрения: (а) обучение элитарное, (б) значение широких основ знаний, инновацию и творчество, а также (в) динамику изменений профессий и мест работы. Вместо этого в результате декретированной консультации с работодателями развивается ориентировка на кратковременные интересы, узкие квалификации, внедрение послушания и доступности работника. Такая ориентировка в академическом образовании создает в учебном заведении среду, которая ближе к фабрике, производящей готовые, аттестованные дипломами изделия, а не является местом развития личности и сознательного внедрения общественных изменений и формирования гражданского общества» (выделено в источнике. - Я.Щ.-П.) (Czerepaniak-Walczak, 2013: 37-38).

Таким образом, либерализм как доктрина, участвующая в общественных изменениях, был единственной официальной идеологией перемен в нашей стране, в том числе перемен в просвещении. А реально основой общественных практик, в том числе образовательных, стал неолиберализм, главной целью образования, в том числе и университетского, - функциональная идентичность по отношению к системе свободного рынка.

Успехи капиталистической экспансии, укрепленной в фундаментальной идеологии роста, привели к таким объемам производства, что проблемой стал сбыт его излишков. В этом источник стремления производителей заменить действия, удовлетворяющие человеческие потребности, на действия, ведущие к обобщению еще несуществующих желаний и намерений. Тем самым в центре внимания оказалась человеческая идентичность и способы ее подчинения цели производителей и работников услуг. Реализованная политика идентификации позволила переориентировать «общественный дискурс с рефлексией над общественной структурой, более всего способствующей либеральной концепции индивида, на раздумья об индивидах, которые лучше всего подходят к признанной общественной структуре» (Lewartowska-Zychowicz, 2010: 239). Нравственная сила исходит из единичной идеи свободы, но понимаемой как свобода выбора с неограниченными возможностями. Именно так понимаемая свобода потребителя стала орудием эмансипации индивида. Причем свобода - только формальная, потому что не каждый может участвовать в рыночной игре, для этого еще необходима и реальная свобода. В таких условиях единственным доступным способом автодефиниции стала отсылка к доступным выборам, источником которых являются разработанные маркетингом потребительские образцы, содержащие комбинации значений, наборы ценно- 
стей и норм, модели общественной коммуникации и правила построения взаимоотношений с другими. Этот процесс, однако, стал возможен в ситуации деконструкции нарративов эпохи Просвещения и связанной с ней концепции сильного субъекта перед лицом развала государства, а также традиционных уз и общественных ролей, которые были источниками отдельных идентичностей. Таким образом, позаботились о максимальной индивидуализации и обособленности человека, тем самым делая его еще более восприимчивым к формированию структуры его характера (там же: 241-242). 3. Бауман указывает на изменение идентичности с данной на заданную и обременение индивида ответственностью за ее формирование (Bauman, 2000).

Сущностью действия политики идентичности является «переконструирование сущности человеческой идентичности, направленное на расширение чувственной (eros) и импульсивной (thymos) части человеческой Ауши и в то же время редукциюее разумной части (nous), ограниченной Ао функции эффективного Аействия на свобоАном рынке» (Lewartowska-Zychowicz, 2010: 242; также см.: Fukuyama, 2006).

Важную роль в реализации такой политики идентичности выполняют средства массовой информации, которые пропагандируют «коА потребления» (Baudrillard, 2006), а также презентуют «культурный капитал» - произведенный экономической сферой, спонсированный корпорацией словарь икон и метафор, контролируемый авторскими правами, способствующим лингвистической приватизации культуры. В большой степени благодаря средствам массовой информации потребление стало основным принципом индивидуальной и общественной экзистенции, дающей доступ к коммерческой общности, как бы выполняющей требование добровольности, а в реальности часто принимающей обязательный и компульсивный характер (Bauman, 2000).

В создании функциональной по отношению к рыночной системе идентичности школа также принимает участие через так называемые рыночные механизмы образования, поскольку образование, понимаемое как общественная практика конструирования значений, придающих смысл человеческой идентичности, принимает практики конструирования идентичности из дискурсивных общественных практик, в которые оно вписано.

Представленная выше характеристика наших общественных перемен после 1989 г., протекающих в условиях глобализации, и перемен, внедренных реформами, позволяет утверждать, что давление рынка на образование, известное уже давно, в настоящее время значительно возросло и приобрело тотальный характер, а его целью является обучение с малолетнего возраста функциональной идентичности по отношению к рынку. Мы наблюдаем необычайно интенсивное присваивание структур и образовательных практик путем радикальной рыночной идеологии. Они стремятся к полной функционализации специфических для них способов мышления и действий. Эти операции, которые А. Герукс определил как террор неолиберализма, стремятся к полной колонизации разума и производству людей с определенным качеством, заказанным рынком; к формированию функциональной идентичности по отношению к рынку и прибыли. Таким образом, утрачивается эмансипированный смысл образования и, кроме того, создаются условия возврата (удерживания, восстановления) единого, конкретного дискурса общественной структуры типа mono ${ }^{1}$ и рациональность типа «должно» (Rutkowiak, 2002: 81). Следовательно, образование подчинено реализации цели, которая не является сознательной целью его участников, что служит причиной того, что сознательное намерение, имплицируемое разумным намерением, не создает обоснования к действию, не является интерпретацией предпринятых действий, дающих возможность проектировать, контролировать и оценивать. 
Сегодня мы имеем ситуацию, в которой содержание и (или) действие выполняют функцию цели, что усиливает автономизацию средств, которые независимо от цели получают равноправные с ней права и даже становятся выше, чем сама цель. Отсюда центральный вопрос образования ставится следующим образом: как? Хотя, по П. Замойскому, тогда, собственно, неважно, как. Было бы әффективно (Zamojski, 2010). Это означает, что после сравнения цели с содержанием эта форма цели не столько организует, сколько формализует (в значении инструментализации) сам процесс обучения, а также предотвращает каждую трансцендентность как доступ к правде о добре, обеспечивающий правильность решений (работы) воли в постановке цели.

\section{ПРИМЕЧАНИЕ}

1 Определение общественной структуры топо и poli имеет идеальный характер, позволяющий различать тотальный и демократический общественный строй, но эти структуры не являются категориями эмпирическими, описывающими действительность (Zamojski, 2010: 55).

\section{СПИСОК АИТЕРАТУРЫ}

Baudrillard, J. (2006) Spoleczeństwo konsumpcyjne : jego mity i struktury. Warszawa : Wydawnictwo "Sic!". 278 s. (На польск. яз.).

Bauman, Z. (2000) Globalizacja: I co z tego dla ludzi wynika. Warszawa : Państwowy Instytut Wydawniczy. 157 s. (На польск. яз.).

Bauman, Z. (2004) Życie na przemial. Kraków : Wydawniczy Literackie. 205, [3] s. (На польск. яз.).

Chomsky, N. (2000) Zysk ponad ludzi. Neoliberalizm a ład globalny. Wroclaw : Wydawnictwo Dolnośląskie. 143 s. (На польск. яз.).

Czerepaniak-Walczak, M. (2005) Teoretyczne perspektywy podstawy programowej ksztalcenia ogólnego - próba odczytania ich z założeń... i z dyskusji na forum www.isp.org.pl // Rocznik Pedagogiczny. T. 28. S. 85-94. (На польск. яз.).

Czerepaniak-Walczak, M. (2013) Autonomia w kolorze sepii w inkrustowanej ramie KRK. O procedurach i treściach zmiany w edukacji akademickiej // Fabryki dyplomów czy universitas. O "nadwiślańskiej” wersji przemian w edukacji akademickiej/ red. M. Czerepaniak-Walczak. Kraków : Oficyna Wydawnicza "Impuls". 362 s. S. 31-63. (На польск. яз.).

Dudzikowa, M. (2004) Mit o szkole jako o miejscu "wszechstronnego rozwoju" ucznia. Eseje etnopedagogiczne. Kraków : Oficyna Wydawnicza "Impuls". 282 s. (На польск. яз.).

Fukuyama, F. (2006) Koniec czlowieka: konsekwencje rewolucji biotechnologicznej. Kraków : Wydawnictwo "Znak". 312 s. (На польск. яз.).

Klus-Stańska, D., Nowicka, M. (2005) Sensy i bezsensy edukacji wczesnoszkolnej. Warszawa : Wydawnictwa Szkolne i Pedagogiczne. 238 s. (На польск. яз.).

Koralewicz, J., Ziólkowski, M. (2003) Mentalność Polaków. Sposoby myślenia o polityce, gospodarce i życiu spolecznym 1988-2000. Warszawa : Wydawnictwa Naukowe "Scholar" ; Collegium Civitas Press. 276 s. (На польск. яз.).

Kwieciński, Z. (2007) Między patosem a dekadencja. Studia i szkice socjopedagogiczne. Wroclaw : DWSE TWP. 252 s. (На польск. яз.).

Lewartowska-Zychowicz, M. (2010) Homo liberalis jako projekt edukacyjny. Od emancypacji do funkcjonalności. Kraków : Oficyna Wydawnicza "Impuls". 289 s. (На польск. яз.).

Luttwak, E. (2000) Turbokapitalizm. Zwycięzcy i przegrani światowej gospodarki. Wroclaw : Wydawnictwo Dolnośląskie. 324 s. (На польск. яз.).

Potulicka, E. (1994) Strategia korporacyjna i kontrakt w zmianie edukacyjnej i spolecznej // Edukacja wobec zmiany spolecznej / red. J. Brzeziński, L. Witkowski. Poznań ; Toruń : Wydawnictwa "Edytor". 517 s. (На польск. яз.).

Rutkowiak, J. (2002) Dynamika przemian spolecznych — dynamika zmiany nauczyciela // Forum Oświatowe. T. 14. No. 1(26). S. 77-96. (На польск. яз.). 
Rutkowiak, J. (2010) Czy istnieje edukacyjny program ekonomii korporacyjnej? // Potulicka, E., Rutkowiak, J. Neoliberalne uwikłania edukacji. Kraków : Oficyna Wydawnicza "Impuls". 356 s. S. 13-38. (На польск. яз.).

Szkudlarek, T. (2004) Pozór i zmiana: o epistemologicznych unikach pedagogiki - dekadẹ i trochẹ później // Ars Educandi. T. 4. S. 83-104. (На польск. яз.).

Zamojski, P. (2005) Socjalizacja krytyczna. Relacja między kontekstem a celem procesów edukacyjnych jako źródło sensu uspolecznienia // Problemy Wczesnej Edukacji. № 2(2). S. 80-90. (Ha польск. яз.).

Zamojski, P. (2010) Pytanie o cel ksztalcenia - zaproszenie do debaty. Gdańsk : Wydawnictwa Uniwersytetu Gdańskiego. 354 s. (На польск. яз.).

Аата поступления: 23.12.2014 2.

\section{SEARCHING FOR THE ULTIMATE GOAL OF UNIVERSAL EDUCATION \\ J. SWIRKO-PILIPCZUK \\ (UNIVERSITY OF SZCZECIN, POLAND)}

The article is an attempt to find the answer to the question what is being undertaken in Poland's schools of every type and level concerning the ultimate goal of universal education as it has been formulated after 1989, during the years of change and educational reforms.

By means of critical analysis of the current situation in the Polish educational system, we show that the education's content and/or its actions increasingly perform the function of its goal. In the end, we observe the phenomenon of automatization of the means which become independent of an end and grow equally important or even superior to it.

As we show, liberalism was the only official ideology for change in post-1989 Poland, but in the sphere of education its influence over social practices took neoliberal forms. Accordingly, functional identification with the free market system became the main goal of education, including the university level.

Keywords: education, educational reform in Poland, goal of education, neoliberalism.

\section{REFERENCES}

Baudrillard, J. (2006) Spoleczeństwo konsumpcyjne : jego mity i struktury [The consumer society : myths and structures]. Warszawa, Wydawnictwo "Sic!". 278 p. (In Polish).

Bauman, Z. (2000) Globalizacja: I co z tego dla ludzi wynika [Globalization: The human consequences]. Warszawa, Państwowy Instytut Wydawniczy. 157 p. (In Polish).

Bauman, Z. (2004) Życie na przemial. [Life in fragments]. Kraków, Wydawniczy Literackie. 205, p. (In Polish).

Chomsky, N. (2000) Zysk ponad ludzi. Neoliberalizm a lad globalny [Profit over people: Neoliberalism and global order]. Wroclaw : Wydawnictwo Dolnoślaskie. 143 p. (In Polish).

Czerepaniak-Walczak, M. (2005) Teoretyczne perspektywy podstawy programowej ksztalcenia ogólnego - próba odczytania ich z zalożeń... i z dyskusji na forum www.isp.org.pl [The theoretical prospects of the core curriculum of general education: An attempt at analysis of foundations... and of discussions at the forum www.isp.org.pl]. Rocznik Pedagogiczny, vol. 28, pp. 85-94. (In Polish).

Czerepaniak-Walczak, M. (2013) Autonomia w kolorze sepii w inkrustowanej ramie KRK. O procedurach i treściach zmiany w edukacji akademickiej [The autonomy in sepia in KRK's inlaid frame. On the procedures and content changes in the academic education]. In: Fabryki dyplomów czy universitas. $O$ "nadwislanskiej" wersji przemian wedukacji akademickiej [Diploma mills or universities. On the "Vistula" version of the changes in academic education] / ed. by M. Czerepaniak-Walczak. Kraków, Oficyna Wydawnicza "Impuls". 362 p. Pp. 31-63. (In Polish).

Dudzikowa, M. (2004) Mif o szkole jako o miejscu "wszechstronnego rozwoju" ucznia. Eseje etnopedagogiczne [The myth of the school as a place of "comprehensive development". Essays in ethnopedagogy]. Kraków, Oficyna Wydawnicza "Impuls". 282 p. (In Polish). 
Fukuyama, F. (2006) Koniec czlowieka: konsekwencje rewolucji biotechnologicznej [The end of man: Consequences of the biotechnology revolution]. Kraków, Wydawnictwo "Znak". 312 p. (In Polish).

Klus-Stańska, D. and Nowicka, M. (2005) Sensy i bezsensy edukacji wczesnoszkolnej [Sense and senselessness of early childhood education]. Warszawa, Wydawnictwa Szkolne i Pedagogiczne. 238 p. (In Polish).

Koralewicz, J. and Ziólkowski, M. (2003) Mentalność Polaków. Sposoby myślenia o polityce, gospodarce $i$ zyciu spolecznym 1988-2000 [Polish mentality. Ways of thinking about politics, economy and social life, 1988-2000]. Warszawa, Wydawnictwa Naukowe "Scholar"; Collegium Civitas Press. 276 p. (In Polish).

Kwieciński, Z. (2007) Między patosem a dekadencja. Studia i szkice socjopedagogiczne [Between pathos and decadence: Studies and sketches in sociopedagogy]. Wroclaw, DWSE TWP. 252 p. (In Polish).

Lewartowska-Zychowicz, M. (2010) Homo liberalis jako projekt edukacyjny. Od emancypacji do funkcjonalnosici [The Homo liberalis as an educational project: From emancipation to functionality]. Kraków, Oficyna Wydawnicza "Impuls". 289 p. (In Polish).

Luttwak, E. (2000) Turbokapitalizm. Zwycięcy i przegrani swiatowej gospodarki [Turbocapitalism. Winners and losers of global economy]. Wroclaw : Wydawnictwo Dolnośląskie. 324 p. (In Polish).

Potulicka, E. (1994) Strategia korporacyjna i kontrakt w zmianie edukacyjnej i spolecznej [Corporate strategy and contract under educational and social change]. In: Edukacja wobec zmiany spolecznej [Education in the face of social change]/ ed. by J. Brzeziński and L. Witkowski. Poznań ; Toruń : Wydawnictwa "Edytor". 517 p. (In Polish).

Rutkowiak, J. (2002) Dynamika przemian spolecznych - dynamika zmiany nauczyciela [The dynamics of social change and the dynamics of change in an an educator]. Forum Oswiatowe, vol. 14, no. 1 (26), pp. 77-96. (In Polish).

Rutkowiak, J. (2010) Czy istnieje edukacyjny program ekonomii korporacyjnej? [Is there an educational program for corporate economy?]. In: Potulicka, E. and Rutkowiak, J. (2010) Neoliberalne uwiklania edukacji [The neoliberal entanglements for education]. Kraków, Oficyna Wydawnicza "Impuls". 356 p. Pp. 13-38. (In Polish).

Szkudlarek, T. (2004) Pozór i zmiana: o epistemologicznych unikach pedagogiki - dekadẹ i trochẹ później [Appearance and change: On the epistemological phenomena in pedagogy - a decade and a little later]. Ars Educandi, vol. 4, pp. 83-104. (In Polish).

Zamojski, P. (2005) Socjalizacja krytyczna. Relacja między kontekstem a celem procesów edukacyjnych jako źródlo sensu uspolecznienia [Critical socialization. The relationship between the context and purpose of the educational process as a source of socialization]. Problemy Wczesnej Edukacji, no. 2 (2), pp. 80-90. (In Polish).

Zamojski, P. (2010) Pytanie o cel ksztalcenia - zaproszenie do debaty [The purpose of education - an invitation to debate]. Gdańsk, Wydawnictwa Uniwersytetu Gdańskiego. 354 p. (In Polish).

Submission date: 23.12 .2014$.

Щвирко-Пилипчук Янина - $\mathrm{PhD}$, доцент, заместитель директора по воспитательной работе Института педагогики Щецинского университета (Польша). Aдpec: 71-431, Polska, Szczecin, ul. Ogińskiego 16/17. Тел.: (8-10-48) (91) 444-37-53. Эл. алpec: swirko2@o2.pl

Swirko-Pilipczuk Janina, PhD, Assistant Professor, Deputy Director for Education, Institute of Pedagogy, University of Szczecin, Poland. Postal address: 16/17, Ogińskiego St., 71-431 Szczecin, Poland. Tel.: (8-10-48) (91) 444-37-53. E-mail: swirko2@o2.pl 